\title{
Management of chronic urologic pain: When the traditional model fails, ask your friends for help
}

\section{J. Curtis Nickel, MD, FRCSC}

Department of Urology, Queen's University, Kingston, ON, Canada

Cite as: Can Urol Assoc J 2018;12(6Suppl3):S145. http://dx.doi.org/10.5489/cuaj.5319

$\mathrm{C}$ hronic urologic pain remains the highest unmet need in urology. Approximately $8 \%$ of men experience some degree of chronic pelvic or genitourinary pain over the course of a year. A similar or greater number of women experience pelvic and/or bladder pain of urologic origin. For at least a third of these individuals, the pain is moderate to severe, bothersome, and impacts their daily activities and quality of life, including sleep and sexual dysfunction. For some patients, the pain and associated symptoms can be totally disabling. For others, suicidal ideation becomes a possible way out of their misery.

The traditional medical model has failed these urology patients. The list of approved medical therapies for urologic chronic pelvic pain (interstitial cystitis/bladder pain syndrome [IC/BPS] and chronic prostatitis/chronic pelvic pain syndrome [CP/CPPS]) can be counted on less than one hand (dimethylsulfoxide [DMSO] and pentosanpolysulfate sodium for IC/BPS and antibiotics for bacterial prostatitis). Unfortunately, even those few interventions have not shown significant efficacy in the majority of patients suffering from urologic chronic pain syndromes.

The research - and there have been significant, wellfunded studies - into etiology and pathogenesis has not shed any light on how to improve management. The pharma- ceutical companies, realizing the potential financial windfall in finding a cure for these conditions, have not discovered a magic bullet. Guidelines, where they exist, can help in some cases, but fail our patients so miserably in others.

So what is a urologist to do? We must continue to see these patients. As it has turned out, they have nowhere else to go. As committed as we are, we need help. And as always been the case, when in trouble, the best solution is to ask a friend for help. And that is what we did for this special CUA/ supplement, funded fully by the Canadian Urological Association as an orphan topic. None of the authors really want to be considered an expert in the field that they have tackled, but they are all committed to proper evaluation and optimal management of these very difficult patients. Over the years they have reviewed the literature, attempted to follow guidelines if possible, experimented with what worked (and learned what did not work), and over time, developed a strategy to deal with this enigmatic chronic pain condition we see in urology. And so this supplement, dedicated to all the patients who have taught us the difficult lessons, is a practical approach by your Canadian colleagues who have been there, done that, and in doing so, have improved the quality of chronic urologic pain management in Canada.

Correspondence: Dr. J. Curtis Nickel, Department of Urology, Queen's University, Kingston, ON, Canada; jin@queensu.ca 